\title{
Tendon Disorders and Gender: Research Perspectives
}

\author{
Guerra Flávia Da Ré* \\ Department of Anatomy, Federal University of Alfenas, Brazil
}

*Corresponding author: Guerra Flávia Da Ré, Federal University of Alfenas-UNIFAL-MG, Department of Anatomy, Brazil, Email: unifal.flavia@gmail.com

Submission: 㭗 October 13, 2017; Published: 㭗January 24, 2018

\section{Introduction}

Tendon lesions are very common and may affect people in their daily activities, work or sports practice. Given the high rate at which such injuries happen, its treatment represents an important share of the health system and of the sport industry [1]. Injuries involving musculoskeletal system are the major causes of suspension of athletes from their activities. Also, tendon and ligaments damage are the leading reason why people seek medical care, regarding musculoskeletal disorders [2,3]. Tendon lesions may be classified as chronic, e.g. tendinitis, or acute, were total or partial tendon rupture occurs. Such rupture may be preceded by chronic inflammation or happen without any previous lesion [1]. According to Szaro et al. [4], tendon lesions are usually related to factors like chronic disease (including diabetes and rheumatoid arthritis), age and gender.

Studies have shown that tendon injuries are especially common among men between 30 to 49 years old and women after menopause [5,6]. Despite these data the great majority of researches are performed using only male animals, usually rats and mice. Performing a quick search, it is hard to find studies involving tendon rupture or injuries in female animals, and the few ones found are frequently restricted to case studies. In fact, even though there is a consensus that estrogen is an important factor in different musculoskeletal components physiology $[7,8]$, its role in the biology and pathological processes involving tendons has been receiving minor attention by the researchers. Just to put it into context, according to Leblanc [9] a search in scientific literature using the terms "tendon" and "estrogen" provided 84 results. On the other hand, "bone" and "estrogen" returned 16,717 matches.

It is known that $95 \%$ of the tendon dry mass in composed by collagen, $60 \%$ of these are type I collagen [1]. The structural arrangements of the collagen fibrils and their association to other extracellular matrix components, such as proteoglycans and metalloproteinases, are responsible for the tendon biomechanical properties [10]. With ageing, there is a decrease in the proteoglycans and water content along with reduction in collagen turnover and in the synthesis of collagenolytic enzymes, predisposing the tissue to lesions [11]. Studies performed with ovariectomized females concluded that estrogen absence leaded to changes in collagen structure in the bone matrix, diminishing the tissue quality [12].

Markiewics [13] observed that estrogen receptors in skin have different roles regarding collagen and metalloproteinases biosynthesis. Other studies associated estrogen reduction with a decrease in the concentration of collagen in the pelvis tendon and ligaments, contributing to pelvic organs prolapse $[14,15]$. All these studies suggest a link between estrogen and collagen explaining, at least in part, women predisposition to tendons injuries. Literature also points to modifications in other components of the extracellular matrix, such as metalloproteinases and proteoglycans. We believe that this poor explored matter is very promising to understand more about the collagen and musculoskeletal system dynamics and particularly to increase our general knowledge on women's health, including some enlightening on the relation of menstrual cycle, menopause and hormone reposition therapy over the tendons, either healthy or after rupture.

\section{References}

1. Nourissat G, Berenbaum F, Duprez D (2015) Tendon injury: from biology to tendon repair. Nat Rev Rheumatol 11(4): 223-233.

2. Riley G (2008) Tendinopathy: From basic science to treatment. Nat Clin Pract Rheumatol 4(2): 82-89.

3. Kaux JF, Forthomme B, Goff CL Crielaard JM, Croisier JL (2011) Current opinions on tendinopathy. J Sports Sci Med 10(2): 238-253.

4. Szaro P Witkowski G, Smigielski R, Krajewski P, Ciszek B (2009) Fascicles of the adult human Achilles tendon-an anatomical study. Ann Anat 191(6): 586-593.

5. Sharma P, Maffulli N (2005) Basic Biology of tendon injury and healing. Surgeon 3(5): 309-316.

6. Thomopoulos S, Parks WC, Rifkin DB, Derwin KA (2015) Mechanisms of tendon injury and repair. J Orthop Res 33(6): 832-839.

7. Cauley JA (2015) Estrogen and Bone health in men and woman. Steroids 99: 11-15.

8. Velders M, Diel P (2013) How sex hormones promote skeletal muscle regeneration. Sports Med 43(11): 1089-1100.

9. Leblanc DR, Schneider M, Angele P, Vollmerc G, Docheva D (2017) The 
effect of estrogen on tendon and ligament metabolism and function. J of Steroid Bioch And Molecular Biol 172: 106-116.

10. Benevides GP, Pimentel ER, Toyama MH, Novello JC, Marangoni S, et al. (2014) Biochemical and biomechanical analysis of tendons of caged and penned chickens. Connect Tissue Res 45(4-5): 206-215.

11. O'Brien M (1997) Stucture and metabolism of tendons. Scand J Med Sci Sport 7(2): 55-61.

12. Cauble MA, Muckley MJ, Fang M, Fang M, Welch K, et al. (2016) Estrogen depletion and drug treatment alter the microstructure of type I collagen in bone. Bone Rep 27(5): 243-251.
13. Markiewicz M, Znoyko S, Stawski L, Ghatnekar A, Gilkeson G, et al. (2013) A role for estrogen receptor alpha $(E R \alpha)$ and estrogen receptor beta (ER $\beta)$ in collagen biosynthesis in mouse skin. J Invest Dermatol 133(1): 120-127.

14. Montoya T, Maldonado JF, Acevedo RA (2015) Effect of vaginal or systemic estrogen on dynamics of collagen assembly in the rat vaginal wall. Biol Reprod 92(2): 43

15. Estanol MV, Crisp SH, Oakley SD, Kleeman SD, Fellner AN, et al. (2015) Systemic markers of collagen metabolism and vitamin $C$ in smokers and non-smokers with pelvic organ prolapse. Eur J Obstet Gynecol Reprod Biol 184: 58-64. 